(82)

\title{
Macrohabitat Selection of the Endemic Endangered Frog Fejervarya greenii (Amphibia: Dicroglossidae) in and around Lentic Water Bodies at Horton Plains National Park
}

\author{
Prabhath M.C., Jayasekara E.G.D.P., Mahaulpatha W.A.D.* \\ Department of Zoology, University of Sri Jayewardenepura, Sri Lanka \\ *mahaulpatha@sjp.ac.lk
}

\begin{abstract}
The macro habitat selection of endemic endangered frog species, Fejerverya greenii was studied in randomly placed plots in and around five lentic water bodies of the Horton Plains National park (HPNP), situated in the highland plateau of the Nuwara Eliya District from January 2016 to December 2016. F. greenii were observed directly on three consecutive days per month.In each plot the number and the maturity stage of $F$. greenii and the distance to the bank of the water body from individuals was recorded. Where possible $F$. greenii was captured, the body surface temperature, relative humidity, habitat relative moisture, substrate availability, substrate temperature and ambient temperature was measured. One-way analysis of variance test was used to analyze the monthly variations in relative humidity, substrate relative moisture and average ambient temperature in the plots. Pearson correlation analysis was used to identify the relationship between body surface temperature and the ambient temperature and substrate temperature. During the study period, 164 individuals were recorded. Presence of $F$. greenii was recorded only in the area of $1 \mathrm{~m}$ to the water and $3 \mathrm{~m}$ to the terrestrial habitats in the lentic water bodies. Though the substrate relative moisture significantly affected the macro habitat selection $(\mathrm{p}<0.05)$ relative humidity and ambient temperature did not significantly affect the macro habitat selection. There was a significant correlation of the body surface temperature with the substrate temperature and water temperature. The study also revealed the selection of macro habitats by different maturity stages. The present study confirms the semi aquatic status of $F$. greenii and suggests $F$. greenii as a habitat specialist preferring in and the immediate surroundings of lentic water bodies.
\end{abstract}

Keywords: Macro habitat Selection, Fejervarya greenii, Horton Plains National Park 